\title{
Applied Aspects of Behavioural Sciences in Prosthodontics
}

\author{
Krishna Prasad D. ${ }^{1}$, Anupama Prasad D. ${ }^{2}$ \\ ${ }^{1}$ Department of Prosthodontics, A B Shetty Memorial Institute of Dental Sciences, NITTE (Deemed to \\ be University), Mangaluru, Karnataka, India. ${ }^{2}$ Department of Prosthodontics, A B Shetty Memorial \\ Institute of Dental Sciences, NITTE (Deemed to be University), Mangaluru, Karnataka, India.
}

\section{ABSTRACT}

\section{BACKGROUND}

Diagnosis and treatment planning is one of the essential measures before starting any treatment and must include considerations of the biological, psychological, social, and economic status of the patient in addition to the obvious dental problems. Patients who approach a dental surgeon for treatment usually demand realistic replacement of the lost tissues, be it hard or soft tissues. Patients usually have an unrealistic expectation about the replacement and always think that artificial substitutes will surpass the natural tissues lost both in aesthetic and functional aspects. It is impossible to the dental surgeons to deal with few patients if he is not able to assess the mental attitude of the patient and programme his treatment accordingly. It is the greatest challenge to the dental surgeon to meet the patients mind and satisfy his expectations.

This article aims to provide a review of the mental and emotional factors involved in prosthodontic treatment and the methods to develop the right attitude towards the patients. Literature has recognized a relationship between psychology and dentistry and has attempted to describe the factors that require consideration during dental therapy. A practical approach to patient management now replaces the theoretical approaches. It is imperative to understand the individual carrying the ailment and his/her psychological background as familiarity with the biological and organic aspects of disease alone is not passable for the successful prosthodontic rehabilitation. Mental attitude of the patient helps us visualise the prognosis of treatment in prosthodontic patients especially the geriatric patients.

\section{KEY WORDS}

Psychological Management, Personality, Motivation, Geriatric, Communication, Gagging
Corresponding Author:

Dr. Anupama Prasad D.,

Reader,

Department of Prosthodontics,

A B Shetty Memorial Institute of Dental

Sciences, NITTE (Deemed to be University),

Deralakatte, Mangaluru-575018,

Karnataka, India.

E-mail: dranupamaprasad@nitte.edu.in

DOI: $10.14260 / j e m d s / 2020 / 283$

Financial or Other Competing Interests: None.

How to Cite This Article:

Prasad KD, Prasad AD. Applied aspects of behavioural sciences in prosthodontics. J. Evolution Med. Dent. Sci. 2020;9(15): 1305-1309, DOI:

10.14260/jemds/2020/283

Submission 03-01-2020,

Peer Review 20-03-2020,

Acceptance 27-03-2020,

Published 13-04-2020.

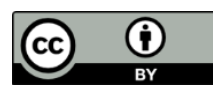




\section{BACKGROUND}

It is not sufficient to know the biological and organic aspects of a disease only. It is crucial to understand the person having the disease and his psychological background. Although communication is essential, it is believed by Prosthodontists that they have common sense and skills are an innate part of their personality. Technical abilities overpower behavioural skills. However, a study attempted to prove that subjects considered necessary that a dentist, in general, places equal importance to communication and understanding along with technical competency of dental specialist.[1] Therefore an understanding of applied aspects of behavioural sciences plays a vital role in the success of our treatment procedures.

\section{Motivation as Related to Prosthodontics}

Dependency and the dominant needs of subjects lead to a varied psychological response to their disabling illness. Motivation is one of the prime objectives before starting any treatment modalities for an issue. Until the subjects are sufficiently motivated about their treatment and understand the positive and negative facts of their therapy, the rehabilitation cannot be successful. Moreover, a prosthodontist can fulfil the requirements like maintenance of health and development of the appearance, only if the subject is entirely motivated.[2]

\section{PERSONALITY AS RELATED TO PROSTHODONTICS}

In 1950, Dr M. M. House,[3] (House Classification of Patient Minds) gave a classification system on the basis of edentulous subjects' psychological responses and adaptation to dentures.

\section{Philosophical Mind}

These subjects believe their dentist completely and follow their advice sincerely. These subjects are most cooperative of all the subjects.

\section{Exacting Mind}

Exacting-mind subjects are compromised in health and require extensive treatment, but are suspicious to accommodate suggestions from the prosthodontist. These subjects also doubt the clinician's ability to treat them and demand extraordinary efforts and guarantees of the treatment.

\section{Hysterical Mind}

These subjects are extremely apprehensive about undergoing dental treatment. They do not accept responsibility for any of their dental problems. Unless the attitudes of such subjects are changed, the probability of successful dental treatment is minimal.

\section{Indifferent Mind}

Indifferent subjects are characterized by a lack of motivation about their existing oral conditions. These subjects tend to ignore instructions and are uncooperative throughout the dental treatment.

Simon Gamer et al. ${ }^{[4]}$ revisited the House classification and found that the psychology of both practitioners, and the subject, determines amount of adaptation of the dentist to the needs of subjects. The new classification had the subjects and the dentist as determiners for outcomes of the treatment, regardless of whether the subject is edentulous or dentate.

\section{The Ideal Patient}

This subject is similar to philosophical class of House classification, is reasonably composed, and express trust on the prosthodontist. These subjects are strongly motivated for their treatment.

\section{The Submitter Patient}

This type of subjects is incapable of providing genuine informed consent because they have surrendered the use of critical faculties and therefore, cannot be an active partner in the treatment.

\section{The Reluctant Patient}

These subjects lack trust on prosthodontist and are suspicious of the treatment plan.

\section{The Indifferent Patient}

Usually forced to seek treatment of prosthodontist by a concerned family member or friend, the indifferent subject is minimally engaged and is least worried about their treatment.

\section{Resistant Patient}

Finally, there is a resistant subject. This subject corresponds to House's exacting mind and Boucher's critical subject. The resistant subject is, paradoxically, very engaged with the dentist, but rather than being dependent, they challenge the dentist. And, like the indifferent subject, there is no trust.

\section{Challenges to the Prosthodontist while Treating Geriatric Subjects}

It is a common belief that age, and ability are inversely proportional. Intellectual functioning is complex, with several components that tends to improve with age rather than deteriorate. Neurophysiologic changes in sensorymotor system may cause difficulties in communication in few subjects. There is evidence that apparent differences in intelligence may be related to a difference between "crystallized" and "fluid" intelligence. "Fluid" or flexible intelligence may decrease with age, while crystallized intelligence usually remains constant or may even increase." Therefore, the management of the geriatric subject can be made more accessible if the prosthodontist builds upon existing subject skills and habits, working with the subject to achieve a mutually desired goal. [5] 


\section{Communication with Subject - The Prosthodontist Patient Relationship}

The relationship between the prosthodontist and the patient is very similar to traffic on a freeway. In one direction, there is a flow of information that involves problems, hostilities, misconceptions, ignorance, fears, and hopes. In the opposite direction, there is a flow of information involving sympathy, patience, advice, education science, and skill. The success of the treatment is mainly dependent on the clinician's communication skills.

\section{Verbal Communication}

In verbal communication, the subject is active, and the dental specialist is passive.

\section{Use Positive Language}

Explain what the subject may feel, and not what they will not feel. For example, within the dental situation, the oftenused phrase "this won't hurt" takes on a new and unintended meaning. The sentence could be rephrased effectively to "as you relax, this will feel much more comfortable for you

\section{Dental Language}

The language which the subject can understand should be used Using the dental language can create misunderstandings and subject may lose trust in the Prosthodontist.[6]

\section{Non-Verbal Communication}

Prosthodontist-subject interaction[7] comprises of four nonverbal areas namely Environmental, Perception and personal space, behaviour of touch and physical actions of nonverbal communication

\section{Factors of Environment}

Situations in the clinical set up may be influenced by environmental factors. Few examples are furniture, lighting, temperature their arrangements which will have an indirect influence on the patient's psychological comfort.

\section{Proxemics}

Perception and use of one's personal and social space is studied in Proxemics. It is classified based into four subcategories by Hall. Actual contact -18 inches as Intimate contact, 1-4 feet as casual-personal space, 4-12 feet as socialconsultative space and 12 feet to visible or audible range as public distance. The prosthodontist must invade the subject's personal space for the treatment of the subject. Although social -consultative distance is the ideal distance for interaction, they gradually get converted to intimate distance interaction unknowingly.

\section{Touch}

Communication through tactile stimulation is personal, sensual and intimate human interaction. It becomes essential for the dental surgeon to remember that subjects may try some evasive actions to overcome the feeling of anxiety and discomfort.

\section{Physical Behaviour}

\section{Gestures}

As reported by Krout, state of fear is represented by handto-nose gestures, aggression is represented by gesture of fist, shame represented by finger at lip and frustrated feeling by hanging open hands between legs. [7] These gestures can help in psychological evaluation of the subject.

\section{Eye Contact}

It has been reported that, the greater the positive feeling of liking for another individual, the greater will be the eye contact with that individual. [7]

\section{Psychological Aspects of Gagging in Prosthodontics}

Whether it is Diagnosis, intraoral examination, radiography or active treatment any step can be associated with Gag reflex. Aetiology of gag reflex can be multifactorial. Literature has marked two main groups namely, Somatogenic and Psychogenic. Gagging is induced by physical stimulus in the former group and by psychologic stimulus in the latter group. Management techniques vary depending on the type of stimulus.

\section{Relaxation}

Relaxation is an effective method to overcome the thought process. For example, a tense patient is helped by guided relaxation of muscles usually starting from lower extremities of leg continuing upwards with reassurance in a serene environment. [8]

\section{Distraction}

The subject can be distracted from the stressful situation by various means like a conversation, concentrating on some paintings, raising one leg during the procedure etc. [8]

\section{Systematic Desensitization}

Gagging thresholds are minimised by progressive techniques of desensitization. A gradual increment in stimulus exposure like object size or duration of placement of objects intraorally is one of the tested methods of desensitization. ${ }^{[8]}$

\section{Training Bases}

Use of training base is a further desensitization technique, whereby a subject should have a progressive supply of various sizes of denture bases.[8]

\section{Errorless Learning}

The subject is instructed to position the denture closer each day and eventually into the mouth in "successive approximations" [8]

The most severe problem associated with the subject with an overactive gag reflex is the strong potential for 
compromised treatment, so every effort should be made to modify the psychological aspect of these subjects.

\section{Psychological Considerations in Subjects Requiring Maxillofacial Rehabilitation \\ The mental trauma associated with severe facial deformity must be immense, as the face is the most essential nonverbal means of communication.}

\section{Confidence}

Some people may gain confidence with the prostheses thinking that it is better than the defect. But some subjects are never satisfied with prostheses. We cannot give the subject the prosthesis of real tissue, but we can modify his/her attitude towards the prostheses. Emphasis must be placed on the quality of life that they can achieve with a functional prosthesis. [9]

\section{Maintaining Subject Dignity}

Restoration of facial appearance can be just as important, even when facing impending premature death like in various cancer subjects. The subjects want to preserve their pride with the help of the prostheses. [9]

\section{Social Attitude}

A well-constructed prosthesis can relieve the subject from attracting morbid attention, pity, and responses of shock from the general public.[9] The prosthodontist must be receptive and accepting of the subject so that the subject will feel comfortable in sharing his fears and conflicts, which will help in providing a quality life to the subject.

\section{Psychological Considerations in Temporomandibular Joint Disorder Subjects}

The most frequent sign at the presentation of TMJ disorders is pain. Pain is located in the masticatory muscles, the preauricular area, and the TMJ. The pain perception process is a result of psychological factors. An increase in levels of emotional stress can lead to an increase in the tonicity of head and neck muscles along with levels of nonfunctional muscle activity such as bruxism or tooth clenching. Subject evaluation for emotional causes of TMJ disorders is one of the most crucial aspects of the treatment of temporomandibular disorders. Treatment with alternative approaches of Psychological and Dental aspects are found to be promising.[10]

\section{Psychological Consideration in Aesthetic Dentistry}

Smile, an element which enhances facial aesthetics is an integral part of face can be successfully restored by a thorough knowledge of one's psychology and personality. Success of any treatment is the sum total of patient willingness to undergo treatment, his belief on operator, readiness for any change, his desires, motivations and selfesteem and communication capacities of the operator.[11]

\section{Psychological Considerations in Implant Dentistry}

One of the consequences of aging is a reduced capacity in adapting to removable dentures. Consequently, in some subjects, denture wearing will have a negative impact on functional, psychological, and social well-being. Subjects' motivations for seeking implant treatment involve issues of comfort, chewing, self-confidence, and appearance. Implant therapy provides benefits to the subject not only in terms of function and aesthetics but also in terms of improvements in quality of life.

\section{Psychological Evaluation of the Subject}

Greeting the subject on arrival would be the best connection of operator to patient than meeting him/her directly on the dental chair.

\section{Body Types}

Prognosis of treatment can be closely related to patient body types, inelastic mucosa with difficult tolerance to denture wear is observed in ectomorphs who are thin subjects, Endomorphs who are impressed by personality of dental surgeon than the treatment per say and are characterised by increased fat and large built. On the other hand, we have mesomorphs with hard physique who are very critical about the treatment perfection. [12]

\section{Shaking Hands with a Subject}

A non-co-operative subject usually has lifeless dead fish type shake of hands relieving his lack of interest. A subject who pretends to believe only with the intention to impress but is actually lacks security has vice like grip during handshake. The best subject to treat would be a patient with firm but normal handshake. [12]

\section{Open Mouth}

Attitude of a subject towards dental treatment will be evident in the manner the patient opens his mouth during treatment procedures.

\section{History Taking as an Important Step in Effective Communication and a Psychological Evaluation of the Subject}

Patient history plays a vital role in older individuals to keep a close check on dental, medical and psychological factors that has directed the patient to demand for dental treatment.

\footnotetext{
Active listening

A subject revealing their history is giving much more than a simple narrative. A prosthodontist should be aware of the sense of the actual words the subject uses. [6] Proper attention given to patients' complaints can help the specialist to deliver successful prosthesis and establishing a rapport with the patient.
} 
Obtaining Accurate Information

A prosthodontist should try to get an opportunity to know the subjects, their wants, needs, and feelings, rather than seeing them merely as a collection of medical conditions and dental diseases. [6]

\section{Affirmation}

Constant affirmation and validation should be given to the statements of the subjects by appropriate responses such as, a reflection of expression, (restrained) nod of agreement, para-verbal responses such as "mmm, ah-ah ".[6]

\section{Reflection}

Reflection can be an effective way of encouraging the subject to expand their story, at the same time indicating active listening and increasing rapport. [6]

\section{Silence}

Silence is a valuable tool that is much underused. The subject may take considerable time to process a statement or question you have put to them, possibly because they are disturbed by it or perhaps because they are upset and struggling to find and articulate the right response. A prosthodontist must allow them time to respond without putting further questions. [6]

\section{DISCUSSION}

During the prosthodontic rehabilitation of the patient, the primary concern should be the individual patient and not just the oral cavity. Stress, illness. Personality, social class and response to pain differ in every individual. Patients' personalities and relationships are important factors in prosthodontic care. Careful psychological assessment of the patient is a vital part of any treatment modality, whether it is complete denture rehabilitation, fixed rehabilitation, aesthetics, or management of temporomandibular disorders.

Geriatric treatment is challenge to all Prosthodontists which demands for proper history recording and consideration at all stages of treatment. Evaluation of Dental conditions with thorough examination and treatment based on concepts and principles of treatment.

\section{CONCLUSIONS}

Bodily and social needs dictate human behaviour. The principles of equilibrium or homeostasis direct these needs, wherein man attempts to maintain a stable physical and psychological state of being. His behaviour is motivated by stimuli that continuously stream from the external and internal environment.

Prosthodontists are privileged to witness the strength and dignity of man and to support it, which enables the subjects to hold their heads high in the face of hardship and to fulfill their roles as human beings. Life and the inevitability of death are parts of the same existence, and it is up to prosthodontists to listen, to know, what is expected of them, and to help the subjects attain their goals.

\section{REFERENCES}

[1] Parker HC. Applied psychology, an essential adjunct in successful denture service. The J of Prosthet Dent 1953;3(5):672-4.

[2] Silverman SI. The psychological considerations in denture prostheses. J Prosthet Dent 1958;8:582-90.

[3] House MM. The relationship of oral examination to dental diagnosis. J Prosthet Dent 1958;8(2):208-19.

[4] Gamer S, Tuch R, Garcia LT. M.M. House mental classification revisited: Intersection of particular patient types and particular dentist's needs. J Prosthet Dent 2003;89(3):297-302.

[5] Giddon DB, Hittelman E. Psychologic aspects of prosthodontic treatment for geriatric patients. J Prosthet Dent 1980;43(4):374-9.

[6] Simons D, Potter C, Temple G. Communicating with patients. Hypnosis and communication in dental practice, $1^{\text {st }}$ edn. Quintescence Publishing Co. Ltd., 2007: p. 53-62.

[7] Baseheart JR. Nonverbal communication in the dentistpatient relationship. J Prosthet Dent 1975;34(1):4-10.

[8] Bassi GS, Humphris GM, Longman LP. The etiology and management of gagging: a review of the literature. J Prosthet Dent 2004;91(5):459-67.

[9] Wiens JP, Wiens RL. Psychological management of maxillofacial prosthetic patient. Chap - 1. In: Taylor TD, edr. Clinical Maxillofacial Prostheses. $1^{\text {st }}$ edn. Quintessence publishing Co, Inc. 2000: p. 1-13.

[10] Rugh JD, Solberg WK. Psychological implications in temporomandibular pain and dysfunction. Oral Sci Rev 1976;7:3-30.

[11] Davis LG, Ashworth PD, Spriggs LS. Psychological effects of aesthetic dental treatment. J Dent 1998;26(7):547-54.

[12] Brewer AA. Treating complete denture patients. J Prosthet Dent 1964;14(6):1015-30. 